\title{
Dimensions and occlusal patterns in molars of Hystrix brachyura Linnaeus, 1758 (Mammalia, Rodentia) in a system of wear categories
}

\author{
D.J. van Weers \\ Institute of Taxonomic Zoology (Zoölogisch Museum), University of Amsterdam, P.O. Box 4766, \\ 1009 AT Amsterdam, The Netherlands
}

Keywords: Hystrix brachyura, morphology, dentition, occlusal pattern, wear

\begin{abstract}
Molars of 35 skulls of Hystrix brachyura brachyura Linnaeus, 1758 have been studied. Problems with the currently used dental nomenclature are discussed. A positional, numerical system for the indication of occlusal elements, and a system of wear classes for all the different occlusal patterns are presented. Dimensions of the teeth in relation to wear are given, the variation in the occlusal patterns is described and their changes with progressive wear are discussed.
\end{abstract}

\section{Résumé}

Les molaires de 35 crânes de Hystrix brachyura brachyura Linnaeus, 1758 ont été étudiées. Les problèmes de la nomenclature couramment appliquée sont discutés. Un système positionnel, numérique, pour l'indication des éléments de la surface d'occlusion, ainsi qu'un système de classes d'usure pour tous les patrons d'occlusion, sont présentés. Les dimensions des dents en relation avec l'usure sont données, la variation des patrons d'occlusion est décrite, et on discute la modification de ces patrons en relation avec l'usure progressive.

\section{Introduction}

The wide individual variation in dental patterns, combined with the variation depending on the stage of wear, makes that the characters of teeth are of limited significance for distinguishing extant species and genera of porcupines. Nevertheless occlusal patterns have frequently been used as diagnostic characters in descriptions of fossil species. Therefore the aim of this study is to present a description of dimensions and occlusal patterns in relation to the stage of wear of one recent porcupine species. The opportunity for this study was offered by the availability of a relatively large sample of one species, Hystrix brachyura Linnaeus, 1758.

The fossil record of the family Hystricidae is poor, its phylogeny is still badly known and homologies in the morphology of the occlusal surface are not quite clear. As a consequence the currently used nomenclature is not always consistent, it is very complicated and its application in this study would yield unreadable descriptions. Therefore, a more practical system is chosen for the present paper.

\section{Material and methods}

\section{Material}

For this study 35 skulls of Hystrix brachyura brachyura Linnaeus, 1758 from Sumatra are used, 23 of the Instituut voor Taxonomische Zoölogie, Zoölogisch Museum (ZMA) in Amsterdam and 12 from the collections of the Rijksmuseum van Natuurlijke Historie at Leiden. For more data about these specimens, see Van Weers (1979: 221).

\section{Measurements}

As far as possible, the molars were taken from the skulls and occlusal breadth, occlusal length and the 
height was measured with vernier callipers. In total 115 upper and 111 lower molars could be measured. No occlusal breadth measurements could be taken from very young molars, and no breadth and length measurements of teeth with damaged occlusal surface. No height measurements were possible with teeth which could not be removed from the skull. By "height", the distance is understood between the plane of the occlusal surface and the plane parallel with it through the opposite end of the molar or the tips of the roots of a deciduous molar. When a molar has a curved form, as in the upper ones, this is not the largest dimension which can be measured, but it is clearly definable and can be measured easily.

\section{Age-classes of the skulls}

The skulls were divided into age-classes by the degree in which the upper dentition has been developed:

I Only D4 above edge of alveole $(n=2)$;

II D4 present, M1 above edge of alveole $(n=2)$;

III D4 and M1 present, M2 above edge of alveole $(n=7)$;

IV D4, M1 and M2 present, M3 above edge of alveole $(n=5)$;

V P4 has class of wear A or B (for definitions see below), M3 present $(n=2)$;

VI P4 has at least class of wear C, M3 present $(n=14)$;

VII M1 and M2 have an advanced state of wear with class $\mathrm{H} 2$ or $\mathrm{H} 3(n=3)$.

The age-classes I to IV are considered "young", class V is "subadult", VI "adult" and VII "old".

\section{Problems with dental nomenclature}

Stirton's (1935) tritubercular system for Tertiary beavers was applied to porcupines by Hooijer (1946), Bosma (1968), Van Weers (1985) and more recently by Nikiforowa $\&$ Wangenheim (1988). This system, however, appears to be less suited for porcupines. The complicated structure of the occlusal surface of unworn porcupine molars apparently accounts for the fact that, besides one lingual fold recognised by all authors mentioned, Bosma (1968) distinguished three buccal folds in the upper molars of her Hystricidae material, Stehlin \& Schaub (1951) four, Sulimski (1960) five buccal and an anterior one, whereas in the present paper four buccal and one posterior fold are distinguished. Stirton (1935: 392, Fig. 8) recognised and named three folds in upper as well as in lower molars. Hooijer (1946) did not meet a problem because he studied only lower molars, nor did Bosma (1968) for she did not distinguish more than three folds in upper molars too. Stirton (1935: 392, Fig. 8) named the folds in the upper molars of beavers para-, meso-, and metaflexus, and Bosma used these names for respectively the first, second, and third buccal fold, as distinguished in the present paper, in the porcupine upper molars she studied. However, it is not less likely that, judged on the morphology and position of the folds in Stirton's beavers, they are homologous with respectively the second, third, and fourth buccal fold in porcupine molars. Another objection of Stirton's nomenclature is the naming of all islands ("fossettes" and "fossettids") in connection with the names of folds, which inevitably will lead to confusion (e.g. Bosma, 1968: 339 footnote) because the relation between folds and islands is not always the same.

A basis for a more appropriate nomenclature could be looked for in Wood \& Wilson's (1936) widely accepted system for rodent teeth with cusps. But there the anticlines (crests) have been named, whereas molars of Hystricidae are hypsodont, cusps are not developed and the naming of synclines (folds) is more obvious. The cricetid type of tooth presented in that study $(389$, Fig. 1a and 2a) is five-crested with four synclines, and a basically five-crested pattern for Hystricidae seems to be generally accepted (Wood, 1974: 38). However, this pattern can not convincingly be recognised in the lower porcupine molars with only three folds and obscure homologies, so Wood \& Wilson's (1936) nomenclature does not offer a fully satisfying basis for the lower porcupine teeth. But, whether there is an adequate nomenclature or not, it is unpractical 
to describe the differences in occlusal patterns of a large number of individual molars, as is the aim of this study, mainly by the application of morphological names. Therefore a positional, numerical system for the indication of folds and islands is chosen.

\section{Applied dental nomenclature}

For the lateral grooves which continue in the occlusal surface of a molar, the terms "fold", "inflection", "enamel loop" and "re-entrant fold" are used. Stehlin \& Schaub (1950: 8) recommended the term "Synklinale" instead of "fold" because the latter could indicate an anticline as well as a syncline structure. For this paper the term "fold" is chosen and used in the meaning of Stehlin \& Schaub's "Synklinale". These authors also criticized the use of the terms "Schmelzinseln" and "lakes", apparently from a three-dimensional point of view, and they used "Trichter" or "pits" for them. "Islands" are in fact the twodimensional appearance in the occlusal surface of the funnel-like enamel invaginations in axial direction, and for the present study arbitrarily the term "island" is chosen.

For the symbols used in this paper, see Fig. 1 for the upper and Fig. 2 for the lower molars. The above-mentioned enamel invaginations are clearly visible as flattened enamel tubes at the end of the rudimental molars in Fig. 3. For a comparison with the terms of other authors, see Table I. I have not chosen for different symbols for upper and lower molars, for from the context it will always be clear whether an element of an upper or a lower tooth is discussed.

\section{The occlusal surface}

To know the changes by wear in the occlusal surface of a molar, it should be abraded as was done by Bosma (1968) with one upper and one lower molar. This procedure provides an objective series of successive stages of wear, but it does not inform us about the individual variation of the dental pattern

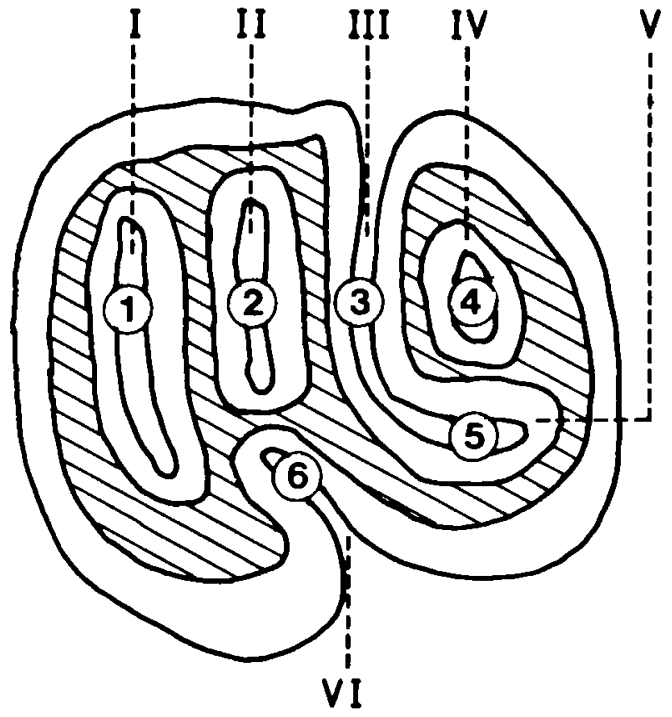

Fig. 1. Review and enumeration of folds (I to VI) and loci of islands ( 1 to 6$)$ potentially present in upper molars of $\boldsymbol{H}$. brachyura. I = 1st bucc. f., II = 2nd bucc. f., III = 3rd bucc. f., IV $=4$ th bucc. $f ., V=$ posterior $f ., V I=$ lingual $f ., 1=1$ st bucc. isl., $2=2$ nd bucc. isl., $3=3$ rd bucc. isl., $4=4$ th bucc. isl., 5 = posterior isl., 6 = lingual isl. Nrs. III and VI are actual folds; I, II, IV, and V closed ones; nrs. 1, 2, and 4 are islands; 3,5 , and 6 loci of potential islands. The figure is based on M1 sin. of ZMA 6866.

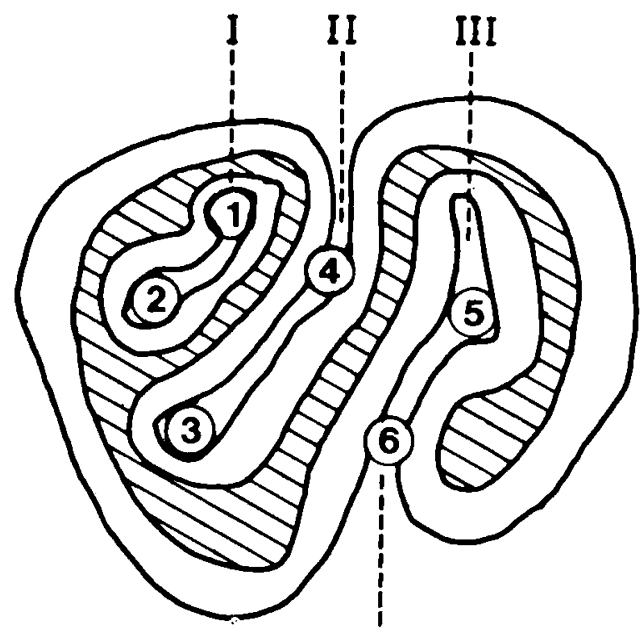

IV

Fig. 2. Review and enumeration of folds (I to IV) and loci of islands (1 to 6) potentially present in lower molars of Hystrix brachyura. I = 1st ling. f., II = 2nd ling. f., III = 3rd ling. f., IV = bucc. f., 1 = 1st ling. isl., 2 = anterior isl., $3=1$ st bucc. isl., $4=2$ nd ling. isl., $5=3$ rd ling. isl., $6=2$ nd bucc. isl. Nrs. II and IV are actual folds, I and III closed ones, 1 and 2 are loci of potential islands in an actual double island, 3 to 6 loci of potential islands. The figure is based on $\mathrm{m} 2 \mathrm{sin}$. of ZMA 6850 . 
Table I. Review and comparison of terms and notations for folds and islands used for porcupine molars. Dash $(-)=$ unnamed. See also Figs. 1 and 2.

\begin{tabular}{llll}
\hline Present paper & Bosma (1968) & Stehlin \& Schaub (1951) & $\begin{array}{l}\text { Wood \& Wilson (1936), } \\
\text { fold posterior of: }\end{array}$
\end{tabular}

\section{UPPER MOLARS \\ $I=1$ st bucc. $\mathrm{f}$. \\ II $=$ 2nd bucc. f. \\ III $=$ 3rd bucc. $\mathbf{f}$. \\ IV $=$ 4th bucc. $\mathrm{f}$. \\ $\mathrm{V}=$ posterior $\mathrm{f}$. \\ $\mathrm{VI}=$ lingual $\mathrm{f}$. \\ 1 = 1st bucc. isl. \\ $2=2$ nd bucc. isl. \\ 3 = 3rd bucc. isl. \\ $4=4$ th bucc. isl. \\ $5=$ posterior isl. \\ 6 = lingual isl.}

\section{LOWER MOLARS}

I = 1st lingual f.

II $=$ 2nd lingual $f$.

III = 3rd lingual $\mathrm{f}$.

IV = buccal fold

$1=1$ st ling. isl.

2 = anterior isl.

$3=1$ st bucc. isl.

$4=2$ nd ling. isl.

$5=3$ rd ling. isl.

$6=2$ nd bucc. isl.
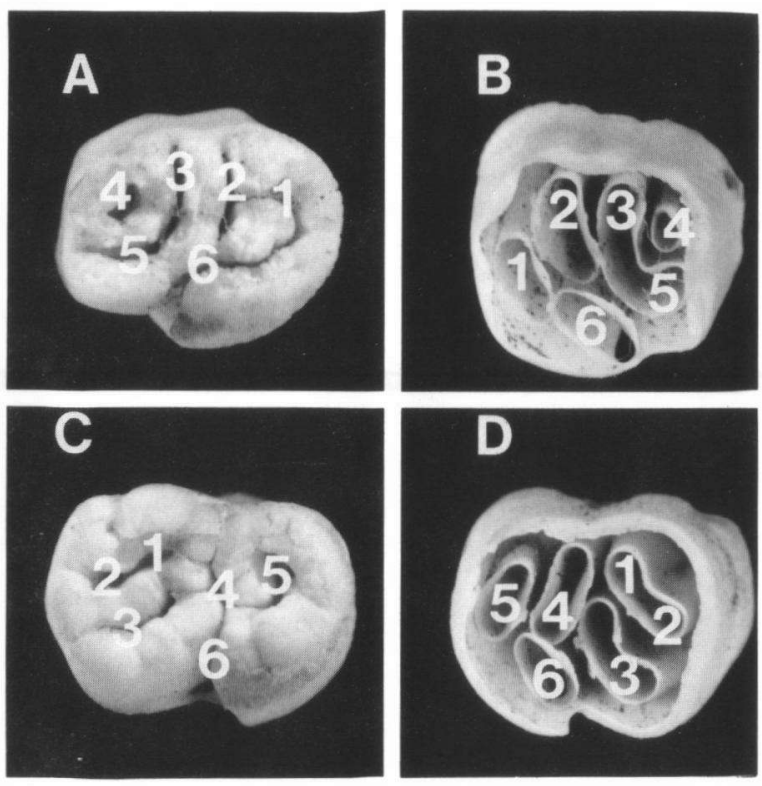

Aussensynklinale I

Aussensynklinale II

Aussensynklinale III

Aussensynklinale IV

$-$

Innensynklinale

parafossette

mesofossette

metafossette 1

metafossette 2

hypofossette

paraflexid

mesoflexid

metaflexid

hypoflexid

parafossettid 1 ?

parafossettid 1 ?

parafossettid 2

mesofossettid

metafossettid

hypofossettid fold posterior of:

$$
\begin{aligned}
& \text { anteroloph } \\
& \text { protolophule } \\
& \text { mesoloph } \\
& \text { metalophule } \\
& \text { - } \\
& \text { protocone } \\
& \text { - } \\
& \text { - } \\
& \text { - } \\
& \text { - } \\
& \text { - } \\
& \text { - }
\end{aligned}
$$

anterolophid +

metalophulid?

mesolophid

hypolophulid

protoconid

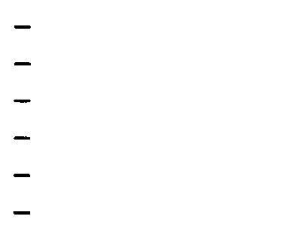

at different wear stages within a species. Abrading a large number of molars has, insuperable, its own objections. The alternative used here is the observation of a relatively large sample of skulls, arranged in order of number of teeth present and to rough degree of wear of the dentitions. On the basis of the sequence of stages of wear in this series and on the differences between subsequent molars in one dentition, classes of wear have been defined.

The overall tendency is that the number of folds decreases with increasing of wear until all folds

Fig. 3. Photographs of occlusal view (A) and opposite end (B) of the rudimental M2 dex., and of occlusal view (C) and opposite end (D) of the rudimental $\mathrm{m} 2 \mathrm{sin}$., derived from closed alveoles of specimen ZMA 6863. In B class of wear Gl, and in D class $\mathbf{T} 1$ is reflected. 
have disappeared, and that in certain stages of wear the first island appears, followed by more, reaching a maximum. In older specimens, the number of islands diminishes until the last one has disappeared in a totally worn tooth. However, a fold in an individual case can be extremely deep and remain to an advanced state of wear, and an island may appear in an unusual early stage of wear. Even a left and right molar of one individual may get different wear classes, so the significance of a certain wear class is not absolute. Although only one breadth, length and height measurement of each pair of molars has been used, the occlusal patterns of both teeth of a pair were determined. The occlusal surface of molars which were too young to be measured, were observed as well.

An extremely large number of patterns is thinkable, but they will not all be realised in one species. In the 128 upper molars studied, 39 more or less different patterns have been recognised, divided over 8 classes (A to $\mathrm{H}$ ), presented in Table II and partly figured in the Plates I and II. For the 116 lower molars studied, 6 classes ( $O$ to $T$ ) with subdivisions have been defined for a total of 33 different patterns, presented in Table III and partly figured in the Plates II and III. Because upper and lower molars show different developments, a common classification is not possible. Only the following rough comparison will hold for most cases: $\mathrm{A}+\mathrm{B}$ $=\mathrm{O}, \mathrm{C}=\mathrm{P}, \mathrm{D}=\mathrm{P}+\mathrm{Q}, \mathrm{E}=\mathrm{P}+\mathrm{Q}+\mathrm{R}, \mathrm{F}=$ $\mathrm{Q}+\mathrm{R}+\mathrm{S}, \mathrm{G}=\mathrm{S}+\mathrm{T}$ and $\mathrm{H}=\mathrm{T}$. Certainly not all possibilities occur in the sample studied and a new specimen may show new patterns. But it is also certain that there is no simple and easy way to describe the characteristics of the morphology of the molars of a porcupine species or a higher taxon.

\section{Description}

\section{Overall dimensions}

In Table IV the dimensions of the measured upper and lower molars, from young to nearly totally worn, up to and including wear classes $\mathrm{H} 2$ and T6, respectively, are presented. The D4 and M3 appear to be clearly smaller than the remaining teeth. The
P4 is indeed only slightly broader and higher than the M1 and M2 but it is clearly longer (mean length P4 = $7.3 \mathrm{~mm}$ against $6.6 \mathrm{~mm}$ of both $\mathrm{M} 1$ and M2). The breadth and height of the $\mathrm{p} 4$ do not differ from those of the $\mathrm{m} 1$ and $\mathrm{m} 2$ but this molar is certainly longer (mean length $\mathrm{p} 4=7.9 \mathrm{~mm}$, against 6.7 and $7.0 \mathrm{~mm}$ of $\mathrm{m} 1$ and $\mathrm{m} 2$ ). Because the M1 and M2 as well as the $\mathrm{m} 1$ and $\mathrm{m} 2$ do not show significant differences, there is no objection to treat these teeth as one sample (respectively $\mathrm{M} 1-2$ and $\mathrm{m} 1-2$ ) as done in Table $\mathrm{V}$.

\section{Dimensions in relation to class of wear}

In Table $\mathrm{V}$ the dimensions of $\mathrm{M} 1-2$ and $\mathrm{m} 1-2$ in relation to their class of wear are presented. Table $\mathrm{V}$ shows that the breadth of the upper molars increases with increasing attrition (mean breadth from $5.3 \mathrm{~mm}$ in class $B$ to $7.3 \mathrm{~mm}$ in $\mathrm{H}$ ), clearly illustrated by the relative breadth of $\mathrm{M1}-2$ in Fig. 4. This is caused partly by the fact that the molars have their largest diameter at half the height of the unworn tooth, and partly because the upper molars are strongly curved in buccal direction. As a consequence, the angle between the occlusal surface and the longitudinal axis of the molar becomes larger with increasing attrition. Sometimes a disproportionate broad occlusal surface with an extreme thin buccal part is the result of that.

The occlusal length is not subject to this feature. From class $\mathrm{A}$ to $\mathrm{F}$ the mean length changes scarcely, and from class $F$ to $H$, as contrasted with the breadth measurements, there is rather a decrease of the mean length from 7.3 to $5.2 \mathrm{~mm}$.

From the means of the height measurements may be read that most of the molars in class $A$ and $B$ are growing still, that most molars have reached their maximum height in $C$ and $D$ and that from $E$ the result of attrition is reflected in the diminishing height. More clearly than by the absolute measurements, this is illustrated by the relative height of M1-2 in Fig. 5, expressed with the ratio height/ occlusal breadth. Table $\mathrm{V}$ shows that the lower molars on an average have reached a full grown breadth in class $Q$ (mean breadth $6.8 \mathrm{~mm}$ ) and do not change much till an advanced state of wear 
Table II. Definitions and subdivisions of classes of wear in occlusal patterns of upper molars with indication of folds in Roman types, islands and loci of islands (loc.) in Arabic numerals, frequency of observed patterns ( $n$ ), connections of folds and islands with hyphen (-).

A: Scarcely any wear, mostly enamel at occlusal surface, little or no dentine visible.

$A 1=6$ folds, most of them mutual connected. $n=4$.

A2 $=6$ folds, some marginal, most folds mutual connected, I situated anterior. $n=1$.

$B$ : Enamel shows wear, dentine visible, no islands formed yet.

B1 $=5$ or 6 folds. Conn.: most of them mutual connected. $n=5$.

B2 $=5$ or 6 folds. Conn.: III-V, VI not connected with one of the folds I to V. $n=3$.

$\mathrm{B3}=5$ folds (II to VI, one may be marginal). Conn.: II-III-V, VI-loc. 1. $n=1$.

B4 $=4$ folds (III to VI). Conn. = VI-loc. 1. $n=2$.

B5 $=4$ folds (I situated anterior, II, V and VI). Conn.: I-VI, VI-V possibly marginal. $n=1$.

C: 1 island formed, 3 to 4 folds left.

$\mathrm{Cl}=$ Isl. 1; 4 folds (II, IV, V and VI). Conn.: V-loc. 3. $n=1$.

C2 = Isl. 2; 4 folds (III, IV, V and VI). $n=1$.

C3 = IsI. 1; 3 folds (II, III and VI). Conn.: III-loci $4+5 . n=1$.

C4 = Isl. 2

C5 = Isl. 4

D: 2 islands formed, 2 to 4 folds left.

D1 = Isl. 1 and 4; 4 folds (II, III, V and VI). Conn.: II-VI and III-V. $n=1$.

D2 $=$ Like D1 but II and VI not connected. $n=1$.

D3 = IsI. 2 and 4; 3 folds (II, V and VI). Conn.: VI-loc. $1 . n=1$.

D4 = Isl. 1 and 4; 3 folds (III, V and VI). Conn.: V-loc. 4. $n=1$.

DS = Isl. 1 and 4; 3 folds (II, III and VI). Conn.: III-loc. S. $n=3$.

D6 = Isl. 2 and 4; 2 folds (V and VI). Conn.: V-loc. 3, VI-loc. 1. $n=1$.

E: 3 islands formed, 2 or 3 folds left.

$\mathrm{E} 1=$ Isl. 1, 2 and 4; 3 folds (III, V and VI). Conn.: III-V. $n=3$.

E2 = Isl. 1, 2 and 5; 3 folds (III, IV and VI). $n=1$.

E3 = Isl. 1, 2 and 4; 2 folds (III and VI). Conn.: III-loc. 5. $n=2$.

E4 = Isl. 1, 2 and 4; 2 folds (V and VI). Conn.: V-loc. 3. $n=1$.

E5 = Isl. 1, 3-5 and 4; 2 folds (II and VI). $n=2$.

F: 3 to 5 islands present, only one fold left (VI).

F1: 3 isl. (1, 2 and 3-4-5 or two of these). $n=3$.

F2: 3 isl. (2, 3-5 and 4 or trace of it). Conn.: VI-loc. $1 . n=1$.

F3: 3 isl. $(1,2-3-5$ and 4). $n=1$.

F4: 4 isl. $(1,2,3-5$ and 4$) . n=12$.

F5: 5 isl. $(1$ to 5$) . n=1)$.

G: 4 to 6 islands present, no fold left.

$\mathrm{Gl}=5$ isl. $(1,2,3-5,4$ and 6$) . n=7$.

G2 $=4$ isl. (1, 2-3-5, 4 and 6). $n=1$.

$\mathrm{G3}=5$ isl. $(1,2-3,4,5$ and 6$), n=2$.

$\mathrm{G} 4=6$ isl. (1 to 6). $n=4$.

G5 $=4$ isl. (1, 2, 3-5 and 6). $n=17$.

G6 $=4$ ial. $(1,2-3,5$ and 6$) \cdot n=1$.

G7 $=5$ isl. $(1,2,3,5$ and 6$) . n=21$.

G8 $=4$ isl. (apparently single ones). $n=8$.

H: Advanced state of wear, 3 to zero islands left.

$\mathrm{HI}=2$ or 3 islands. $n=4$.

H2 $=1$ island left. $n=4$.

H3 = totally worn tooth, not any island left. $n=2$. 
Table III. Definitions and subdivisions of classes of wear in occlusal patterns of lower molars with indication of folds in Roman types, islands and loci of islands (loc.) in Arabic numerals, frequency of observed patterns ( $n$ ), connections of folds and islands with hyphen ( $)$.

O: Occlusal surface divided in several parts by the connection of folds. If dentine is visible, fields separately ringed in by enamel. 0 to 2 islands present.

OI = At least 4 folds present, little dentine visible. Conn.: at least II-III-IV. $n=4$.

$\mathrm{O} 2=4$ folds (I, II, III and IV), dentine clearly visible. Conn.: III-IV. $n=2$.

$\mathrm{O} 3=3$ folds (I, II and IV), no islands formed yet. Conn.: II-IV or I-IV. $n=5$.

O4 = 2 folds (II and IV), no islands formed yet. Conn.: II-IV. $n=1$.

$\mathrm{OS}=2$ or 3 folds present, 1 or 2 islands formed already. Conn.: II-IV. $n=1$.

P: Occlusal surface for the greater part consisting of one dentine field with outer enamel ring of one united whole. No islands formed yet.

Pl $=3$ folds. (I, II, IV). Conn.: I-loci $1+2$ and II-loc. 3. $n=2$.

P2 $=2$ folds. (II and IV). Conn.: II-loci $1+2+3 . n=2$.

P3 = 3 folds (I, II and IV). Conn.: I-II-loci $1+2+3 . n=1$.

Q: 2 or 3 folds present, one island present.

$\mathrm{Q} 1=3$ folds (I, II and IV), 1 island (5). Conn.: I-loci $1+2$ and II-loc. 3. $n=1$.

$\mathrm{Q} 2$ = 2 folds (II and IV), 1 island (1-2). Conn.: II-loc. 3. $n=8$.

$\mathrm{Q3}=2$ folds (II and IV), 1 threefold island (1-2-3). $n=1$.

$\mathrm{Q} 4=2$ folds (II and IV), 1 island (1). Conn.: II-loci $2+3 . n=1$.

$\mathrm{Q} 5=2$ folds (II and IV), 1 island (2). Conn.: II-loc. $1+3 . n=2$.

$R: 2$ folds (II and IV) and 2 or more islands present.

$R 1=2$ islands (1-2 and 5). Conn.: II-IV (dividing occl. surface), $n=1$.

$\mathrm{R} 2=2$ islands (1-2 and 5). Conn.: II-loc. 3. $n=6$.

R3 $=3$ islands (1-2, 3 and 5, or 2, 3, and 5). Conn.: II-loc. 3. $n=1$.

R4 $=3$ islands (1, 2 and 5). Conn.: II-loc. 3. $n=1$.

R5 $=2$ islands ( 1 and 5). Conn.: II-loci $2+3 . n=1$.

R6 $=2$ islands $(1-2-3$ and 5$) . n=1$.

S: Only fold IV left, 2 or more islands.

S1 $=3$ islands (1-2, 3 and 4). Conn.: IV-locus 5. $n=1$.

$S 2=4$ islands (1 to 4 ). Conn.: VI-loc. 5. $n=1$.

S3 $=4$ islands (three out of 1 to 4 , and 5). Conn.: IV-loc. 6. $n=10$.

$S 4=5$ or 6 islands. $n=3$.

S5 $=3$ islands (two out of 1 to 4 , and 5). Conn.: IV-loc. 6. $n=4$.

S6 $=2$ islands ( 5 and 3 or 4 ). $n=1$.

S7 $=2$ islands ( 2 out of 1 to 5 or double ones). $n=1$.

T: No folds, only islands left.

T1: 5 islands ( 1 or 2 or $1-2,3,4,5$ and 6$) . n=19$.

T2: 6 islands ( 1 to 6 ). $n=6$.

T3: 4 islands. $n=10$.

T4: 3 islands $(3,4$ and 6$) . n=6$.

T5: 2 islands ( 3 and 6). $n=4$.

T6: 1 island or a trace of it left. $n=4$.

T7: totally worn, no trace of any island. $n=1$.

(mean breath in $\mathrm{T}=6.6 \mathrm{~mm}$ ). The length of the $\mathrm{m} 1-2$ does not change from $\mathrm{O}$ to $\mathrm{S}$ but does diminish on an average in the last class $T$. Relative breadth of these lower molars is expressed in Fig. 6 with the ratio occlusal breadth/occlusal length and the relative height in Fig. 7 with height/occlusal breadth.
Changes in occlusal patterns by wear

The selection of the wear patterns for the representation in the Plates I to III was in the first place based on the frequency of these patterns, but was further arbitrary. In A1 (Plate I, Fig. 1) fold I is 
Table IV. Overall molar dimensions from measurements of 35 specimens of $H$. b. brachyura Linnaeus, 1758 from Sumatra, in mm with range, mean, number of specimens $(n)$ and standard deviation (s).

\begin{tabular}{|c|c|c|c|c|c|}
\hline $\begin{array}{l}\text { UPPER } \\
\text { MOLARS }\end{array}$ & D4 & P4 & M1 & M2 & M3 \\
\hline $\begin{array}{l}\text { occlusal } \\
\text { breadth }\end{array}$ & $\begin{array}{c}4.6-6.7 \\
5.7 \\
n=15 \\
s=0.6\end{array}$ & $\begin{array}{c}5.6-8.5 \\
7.0 \\
n=16 \\
s=0.8\end{array}$ & $\begin{array}{c}5.0-8.2 \\
6.7 \\
n=30 \\
s=0.9\end{array}$ & $\begin{array}{c}4.8-8.5 \\
6.4 \\
n=28 \\
s=0.9\end{array}$ & $\begin{array}{c}4.9-7.5 \\
5.8 \\
n=19 \\
s=0.7\end{array}$ \\
\hline $\begin{array}{l}\text { occlusal } \\
\text { length }\end{array}$ & $\begin{array}{c}5.3-7.4 \\
6.7 \\
n=15 \\
s=0.6\end{array}$ & $\begin{array}{c}5.3-8.0 \\
7.3 \\
n=19 \\
s=0.6\end{array}$ & $\begin{array}{c}4.7-7.9 \\
6.6 \\
n=30 \\
s=0.8\end{array}$ & $\begin{array}{c}4.9-7.7 \\
6.6 \\
n=28 \\
s=0.7\end{array}$ & $\begin{array}{c}5.2-7.3 \\
6.2 \\
n=19 \\
s=0.5\end{array}$ \\
\hline height & $\begin{array}{c}9.2 \\
n=1\end{array}$ & $\begin{array}{c}9.1-18.3 \\
14.1 \\
n=14 \\
s=2.8\end{array}$ & $\begin{array}{c}6.9-17.8 \\
13.3 \\
n=27 \\
s=2.9\end{array}$ & $\begin{array}{c}6.9-17.1 \\
12.9 \\
n 26 \\
\mathrm{~s}=2.5\end{array}$ & $\begin{array}{c}7.6-13.1 \\
10.7 \\
n=16 \\
s=1.4\end{array}$ \\
\hline $\begin{array}{l}\text { LOWER } \\
\text { MOLARS }\end{array}$ & d4 & p4 & $\mathrm{m} 1$ & $\mathrm{~m} 2$ & $\mathrm{~m} 3$ \\
\hline $\begin{array}{l}\text { occlusal } \\
\text { breadth }\end{array}$ & $\begin{array}{c}4.2-6.1 \\
5.1 \\
n=14 \\
s=0.5\end{array}$ & $\begin{array}{c}4.7-7.1 \\
6.2 \\
n=16 \\
s=0.7\end{array}$ & $\begin{array}{c}5.1-7.5 \\
6.3 \\
n=29 \\
s=0.5\end{array}$ & $\begin{array}{c}4.4-7.6 \\
6.2 \\
n=27 \\
s=0.8\end{array}$ & $\begin{array}{c}4.7-6.1 \\
5.4 \\
n=19 \\
s=0.4\end{array}$ \\
\hline $\begin{array}{l}\text { occlusal } \\
\text { lenght }\end{array}$ & $\begin{array}{c}6.6-8.2 \\
7.6 \\
n=13 \\
s=0.4\end{array}$ & $\begin{array}{c}6.4-9.0 \\
7.9 \\
n=18 \\
s=0.7\end{array}$ & $\begin{array}{c}5.0-8.5 \\
6.7 \\
n=28 \\
s=0.9\end{array}$ & $\begin{array}{c}4.6-8.2 \\
7.0 \\
n=28 \\
s=0.7\end{array}$ & $\begin{array}{c}5.5-7.4 \\
6.5 \\
n=19 \\
s=0.5\end{array}$ \\
\hline height & $\begin{array}{c}10.8-14.7 \\
12.3 \\
n=3\end{array}$ & $\begin{array}{c}8.3-18.9 \\
14.4 \\
n=17 \\
s=2.7\end{array}$ & $\begin{array}{c}7.4-18.1 \\
13.4 \\
n=22 \\
s=2.8\end{array}$ & $\begin{array}{c}8.6-18.4 \\
14.1 \\
n=21 \\
s=2.6\end{array}$ & $\begin{array}{c}7.5-13.2 \\
10.4 \\
n=16 \\
s=1.5\end{array}$ \\
\hline
\end{tabular}

clearly present. In A2 and B5 it seems to be lacking, but there the anterior fold is supposed to be homologous with fold I. In B3 that fold is closed already, but island 1 has not yet been developed because fold VI is still in connection with that locus. The fact that locus 1 can be in connection with fold VI (B1) as well as with fold I (B2), illustrates that it is arbitrary to derive the name of an island from that of a certain fold. Fold II can be connected with fold VI (B1), be isolated rather early (B2) or be connected with III and V (B3). Fold III is in many cases connected with fold V (B4, C5, E1). Folds IV and $\mathrm{V}$ have not been separately named by previous authors, bu they are clearly present: IV pictured in $\mathrm{A} 1, \mathrm{~B} 2, \mathrm{~B} 3, \mathrm{C} 4$, and $\mathrm{V}$ pictured in $\mathrm{A} 1, \mathrm{~A} 2, \mathrm{~B} 1-4$,
C5, D2, D4. As far as observed, fold VI is always the last one that disappears. In class G1 (Fig. 3B and Plate I, Fig. 20) the enamel "tubes" 3 and 5 are still connected, but in a further state of wear (G4 in Plate II, Fig. 1) they separate and a stage with 6 islands appears. In stage G5 the double island 3-5 has not yet split, but island 4 has already disappeared. G7 is the most frequent pattern in the sample studied. There the islands $1,2,3,5$, and 6 can be easily identified. From G8 to $\mathrm{H} 2$ that is no more possible.

In the present study in the lower molars three lingual and one buccal fold are recognised. Not quite clearly in $\mathrm{O} 1$ (Plate II, Fig. 5) but certainly in O2, all four folds can be indicated. Fold III is of less 
Table $V$. Occlusal breadth, occlusal length and height in relation to classes of wear (A to $H)$ of $M 1-2$ and $\mathrm{m} 1-2(\mathrm{O}$ to $\mathrm{T}$ ) in mm with range, mean, frequency $(n)$ and standard deviation (s).

\begin{tabular}{|c|c|c|c|c|c|c|c|}
\hline \multicolumn{4}{|c|}{ M1-2 } & \multicolumn{4}{|c|}{$\mathrm{m} 1-2$} \\
\hline class & breadth & length & height & class & breadth & length & height \\
\hline $\mathbf{A}$ & $\begin{array}{c}5.6 \\
n=1\end{array}$ & $\begin{array}{c}7.3 \\
n=1\end{array}$ & 17.1 & 0 & $\begin{array}{c}4.4-6.0 \\
5.4\end{array}$ & $\begin{array}{c}6.1-8.2 \\
7.4\end{array}$ & $\begin{array}{c}13.6-18.4 \\
16.6\end{array}$ \\
\hline B & $4.8-5.7$ & $6.1-7.7$ & $11.7-16.5$ & & $n=6$ & $n=7$ & $n=4$ \\
\hline & $\begin{array}{c}5.3 \\
n=6\end{array}$ & $\begin{array}{c}7.1 \\
n=6\end{array}$ & $\begin{array}{c}14.8 \\
n=6\end{array}$ & $\mathbf{P}$ & $\begin{array}{c}5.2-6.4 \\
5.7\end{array}$ & $\begin{array}{c}7.0-8.4 \\
7.6\end{array}$ & $\begin{array}{c}15.0-18.1 \\
16.6\end{array}$ \\
\hline C & $5.5-5.9$ & $7.3-7.5$ & $15.5-16.5$ & & $n=\mathbf{3}$ & $n=3$ & $n=3$ \\
\hline & $\begin{array}{c}5.7 \\
n=2\end{array}$ & $\begin{array}{c}7.4 \\
n=2\end{array}$ & $\begin{array}{c}16.0 \\
n=2\end{array}$ & $\mathrm{Q}$ & $\begin{array}{c}5.1-6.7 \\
6.8\end{array}$ & $\begin{array}{c}7.2-8.1 \\
7.5\end{array}$ & $\begin{array}{c}13.1-17.0 \\
15.4\end{array}$ \\
\hline D & $\begin{array}{c}5.5-6.4 \\
5.8\end{array}$ & $\begin{array}{c}6.7-7.5 \\
7.2\end{array}$ & $\begin{array}{c}14.2-17.8 \\
16.1\end{array}$ & & $\begin{array}{l}n=10 \\
s=0.5\end{array}$ & $\begin{array}{c}n=9 \\
s=0.3\end{array}$ & $\begin{array}{c}n=9 \\
s=1.2\end{array}$ \\
\hline & $n=5$ & $n=5$ & $n=5$ & $\mathbf{R}$ & $5.3-6.8$ & $7.4-8.5$ & $13.7-16.3$ \\
\hline $\mathbf{E}$ & $\begin{array}{c}5.3-6.8 \\
6.1\end{array}$ & $\begin{array}{c}7.0-7.9 \\
7.2\end{array}$ & $\begin{array}{c}13.5-16.4 \\
14.9\end{array}$ & & $\begin{array}{c}6.3 \\
n=6\end{array}$ & $\begin{array}{c}7.8 \\
n=6\end{array}$ & $\begin{array}{c}15.5 \\
n=6\end{array}$ \\
\hline & $n=6$ & $n=6$ & $n=6$ & $\mathbf{s}$ & $6.0-6.9$ & $7.3-7.5$ & $12.6-15.5$ \\
\hline F & $\begin{array}{c}5.0-7.1 \\
6.4\end{array}$ & $\begin{array}{c}6.2-7.7 \\
7.3\end{array}$ & $\begin{array}{c}12.0-15.9 \\
14.6\end{array}$ & & $\begin{array}{c}6.5 \\
n=5\end{array}$ & $\begin{array}{c}7.4 \\
n=5\end{array}$ & $\begin{array}{c}13.9 \\
n=5\end{array}$ \\
\hline & $n=8$ & $n=8$ & $n=8$ & $\mathbf{T}$ & $5.6-7.6$ & $4.6-7.4$ & $7.4-13.8$ \\
\hline G & $\begin{array}{c}4.8-8.5 \\
7.1 \\
n=25\end{array}$ & $\begin{array}{c}4.9-6.9 \\
6.2 \\
n=25\end{array}$ & $\begin{array}{c}9.0-14.4 \\
11.2 \\
n=23\end{array}$ & & $\begin{array}{c}6.6 \\
n=26 \\
s=0.5 \\
\end{array}$ & $\begin{array}{c}6.3 \\
n=26 \\
s=0.7\end{array}$ & $\begin{array}{c}10.8 \\
n=16 \\
s=1.5\end{array}$ \\
\hline & $\mathrm{s}=0.7$ & $\mathrm{~s}=0.5$ & $\mathrm{~s}=1.4$ & $\mathrm{O}-\mathrm{T}$ & $4.4-7.6$ & $4.6-8.5$ & $7.4-18.4$ \\
\hline $\mathbf{H}$ & $\begin{array}{c}6.3-8.1 \\
7.3 \\
n=6\end{array}$ & $\begin{array}{c}4.7-5.7 \\
5.2 \\
n=6 \\
\end{array}$ & $\begin{array}{c}6.9-10.5 \\
8.1 \\
n=5 \\
\end{array}$ & & $\begin{array}{c}6.3 \\
n=56 \\
s=0.6\end{array}$ & $\begin{array}{c}7.0 \\
n=56 \\
s=0.8\end{array}$ & $\begin{array}{c}13.0 \\
n=43 \\
s=2.7\end{array}$ \\
\hline $\mathrm{A}-\mathrm{H}$ & $\begin{array}{c}4.8-8.5 \\
6.5 \\
n=59 \\
s=0.9\end{array}$ & $\begin{array}{c}4.7-7.9 \\
6.6 \\
n=59 \\
s=0.8\end{array}$ & $\begin{array}{c}6.9-17.8 \\
12.9 \\
n=56 \\
s=2.8\end{array}$ & & & & \\
\hline
\end{tabular}

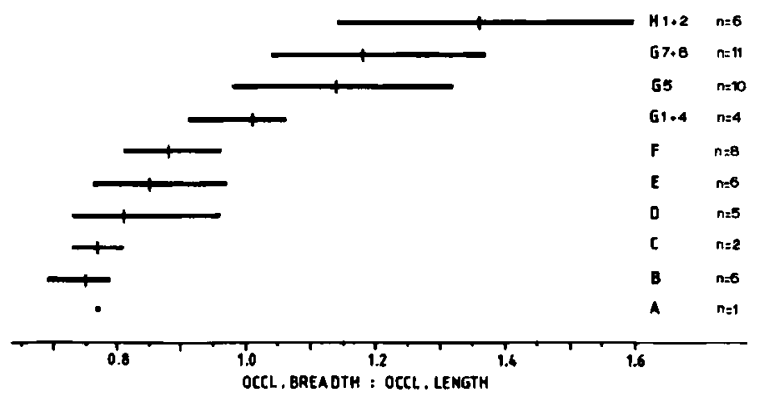

Fig. 4. Relative breadth of $M 1-2$, expressed as the ratio occlusal breadth/occlusal length for the indicated stages of wear, with range, mean and frequency $(n)$. For classes of wear see Table II.

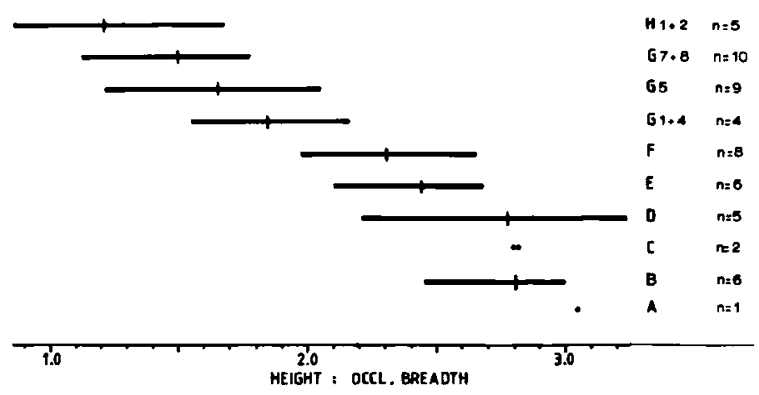

Fig. 5. Relative height of $\mathrm{M1}-2$, expressed as the ratio height/ occlusal breadth for the indicated stages of wear, with range, mean and frequency $(n)$. For classes of wear see Table II. 


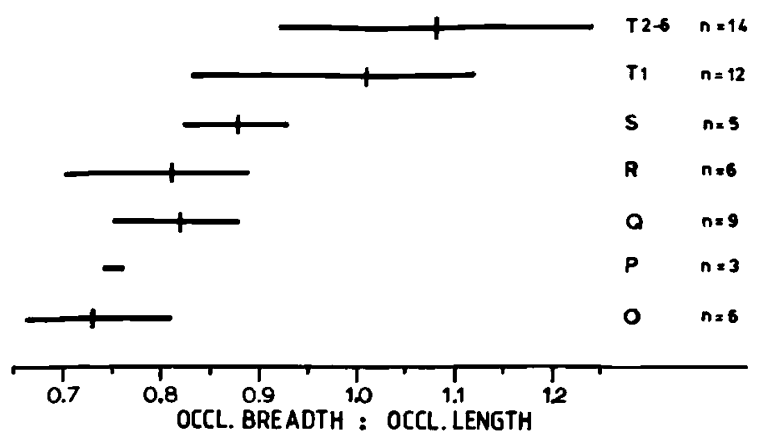

Fig. 6. Relative breadth of $\mathrm{m} 1-2$, expressed as the ratio occlusal breadth/occlusal length for the indicated stages of wear, with range, mean and frequency $(n)$. For classes of wear see Table III.

practical significance because it disappears nearly always in a very early state, but in $\mathrm{O} 2$ it is connected with fold IV. Fold I sometimes disappears early (O3-O5) or stays longer (Q1). In the classes of wear P1-P3 folds II and IV are separated, but in a single case it is possible that the connection still exists when already two islands have been formed (R1). By the closure of fold IV, island 5 is formed, sometimes rather early $(\mathrm{Q} 1)$ but sometimes very late when already four islands have been formed ( $\mathrm{S} 2$ in Plate III, Fig. 5). In S3 at the loci 1 and 2, one island is visible which is split in the separate islands 1 and 2 in S4. In T 1 island 6 has been formed by the nearly full disappearance of fold IV, and the identity of the islands 1 to 4 can no more be established with certainty. The state of wear with five islands may be an earlier one than that with six islands when two enamel tubes are still connected as in Fig. 3D, but in Plate III, Figs. 10 and 11, T2 could present a younger stage than the pictured $\mathrm{T} 1$.

\section{Conclusions and discussion}

The numbers of molars are not evenly distributed over the wear classes and occlusal patterns as defined in Tables II and III. The 6 categories A to F contain 28 more or less different occlusal patterns with 57 molars, whereas in only one class $G$ with 8

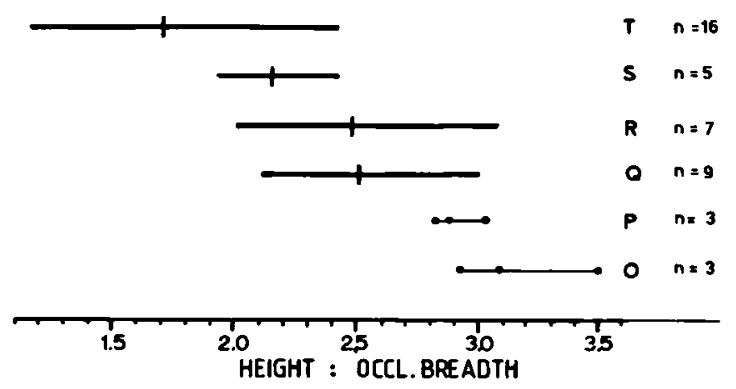

Fig. 7. Relative height of m1-2, expressed as the ratio height/ occlusal breadth for the indicated stages of wear, with range, mean and frequency $(n)$. For classes of wear see Table III.

occlusal patterns 61 teeth are enclosed. This is apparently caused by the fact that in the first traject of attrition of an unworn molar the top region with a very complicated structure is concerned. There the replacement of occlusal patterns will be the result of relatively small amounts of attrition, whereas further down in a larger stretch of attrition fewer changes may occur. This is reflected in the measurements in Table $\mathrm{V}$ where the full-grown M1-2 teeth have a mean height of $16.1 \mathrm{~mm}$ (class D). In class $\mathrm{F}$ this is diminished to a mean height of $14.6 \mathrm{~mm}$, being an attrition of less than $10 \%$ of the mean full-grown height. Only one class further, in $\mathrm{G}$, the mean height is $11.2 \mathrm{~mm}$, being a diminution of $30 \%$ of the mean full-grown height. Comparable conclusions may be drawn from the lower molar patterns in Table III where the largest frequency is found in pattern $T 1$. In the lower molars in Table $\mathrm{V}$ too, the strongest decrease in height is found in the more advanced stages of wear from class $S$ to $T$.

The comparison of Bosma's (1968) description with our results, shows differences as well as similarities. Her hypothethical stage "A1" (op. cit.: 338 , Fig. 1) of an upper molar, fits in our wear class $B$, but is not represented in one of the occlusal patterns of that class. Her "A2" with 3 folds but without islands, and her "A3" with 2 folds and one island, do not fit in one of our defined classes. Three reasons may explain this. It is of course possible that a new specimen, even of the same species,

Plate I. Occlusal view of upper molars with indication of class of wear. Figs. 1, 3, 4, 7, 9, 17, $20=$ M2; Figs. 2, 5, 10-16, 19= M1; Fig. $6=$ M3; Figs. 8, $18=$ D4. All specimens are sinistral ones. All Figures $\times 4$. 

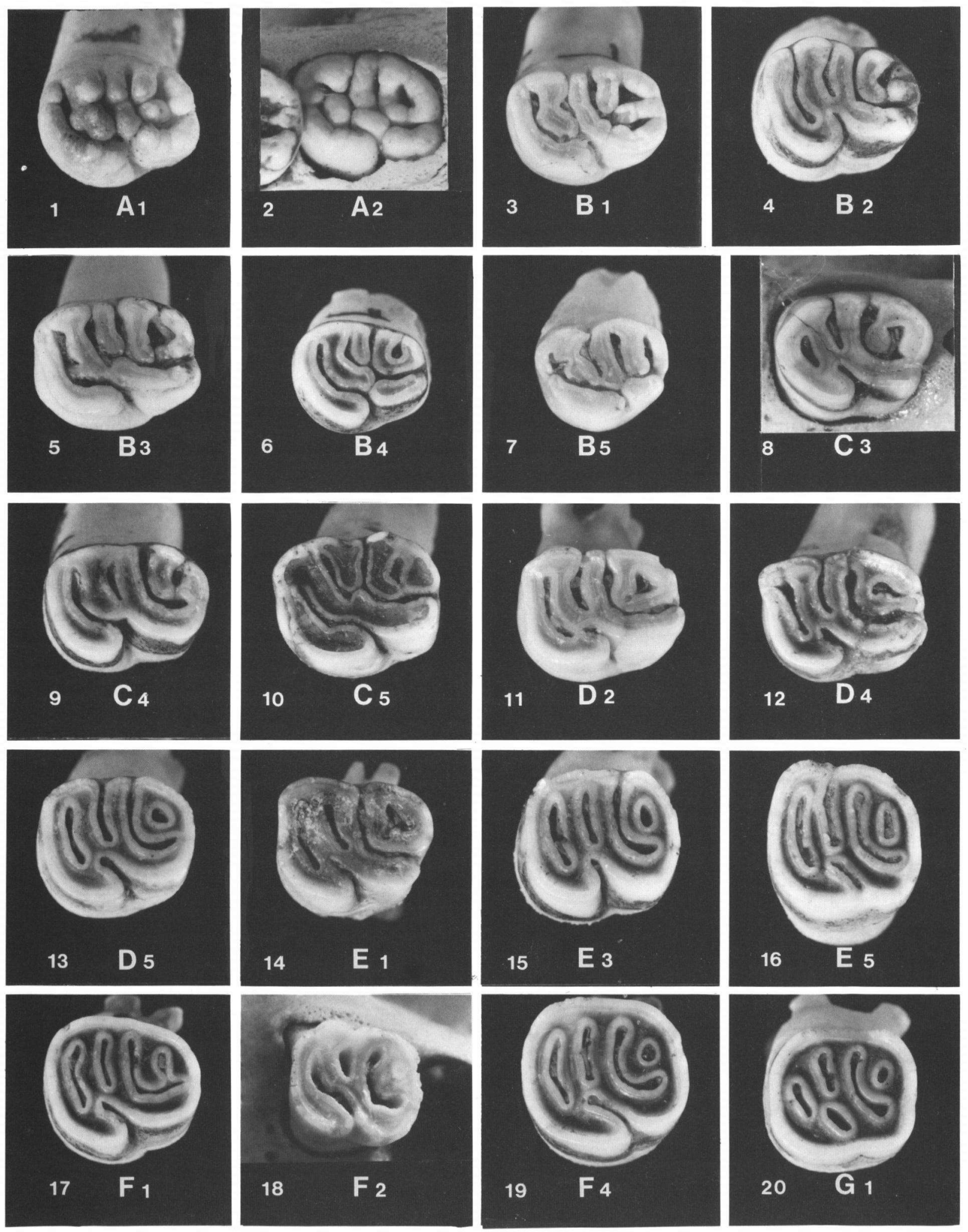

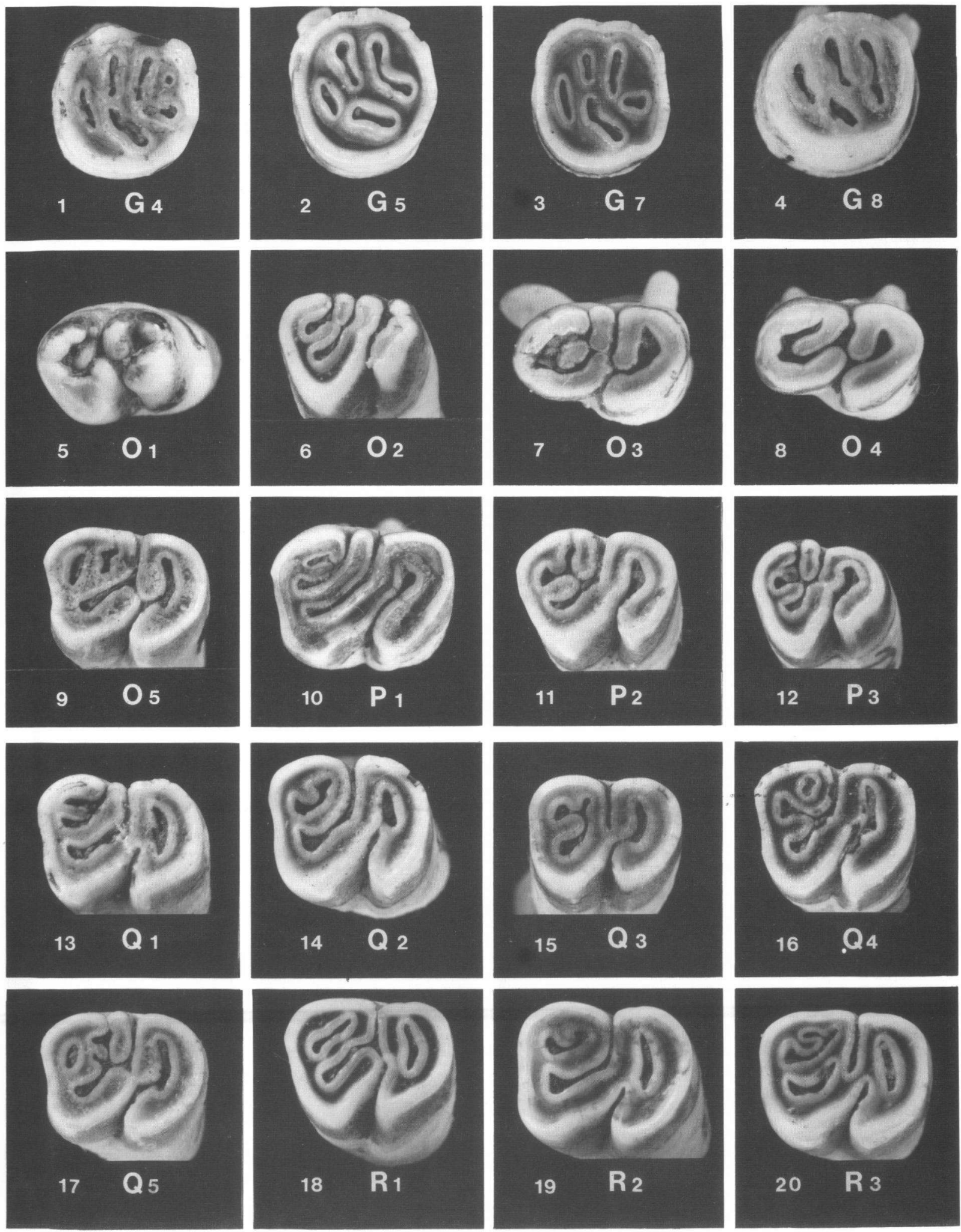

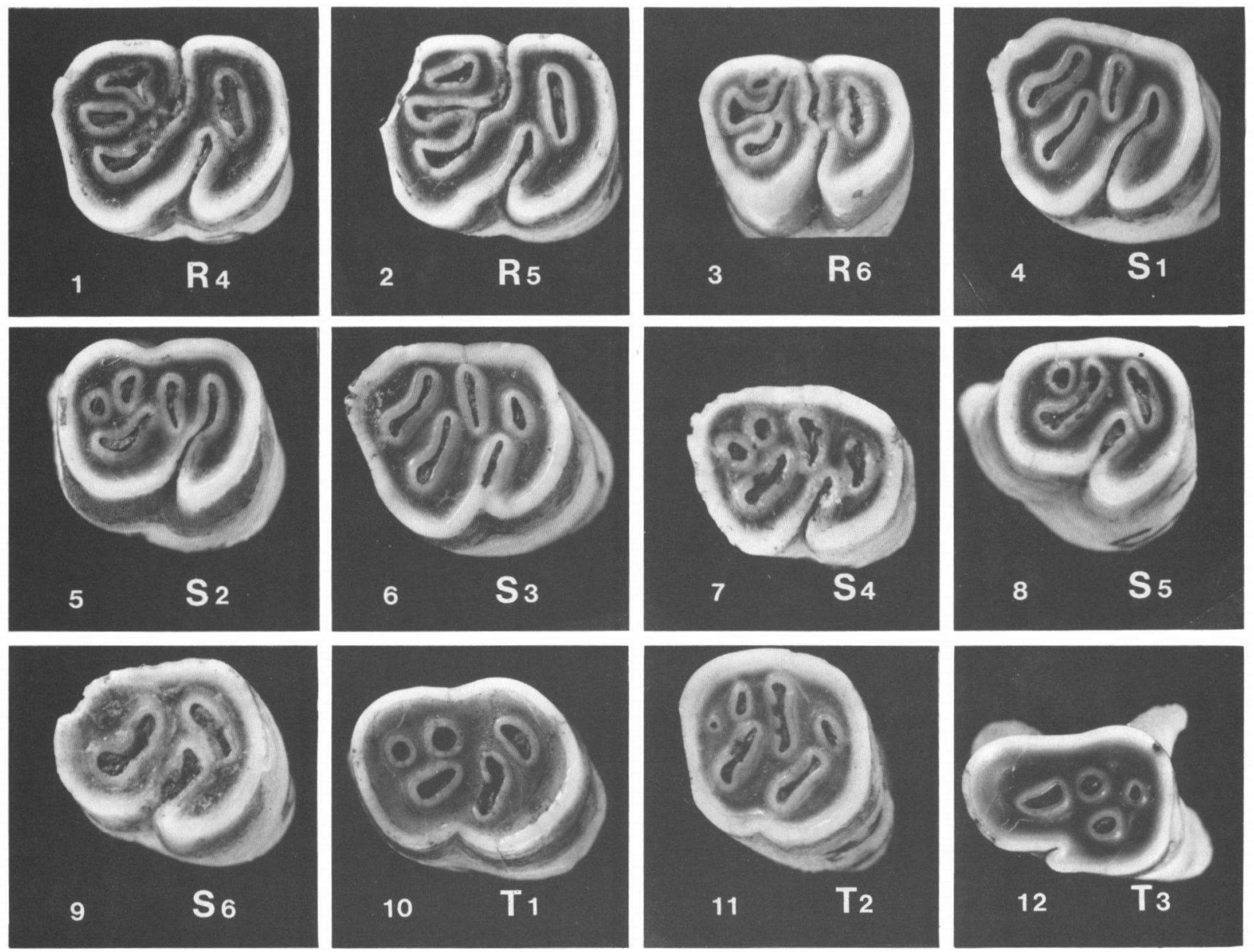

Plate III. Occlusal view of lower molars with indication of class of wear. Figs. 1, $2=\mathrm{m} 1 ;$ Figs. 3, 4, 6, 7, 11 = m2; Figs. 5, 8, 9, 10 $=$ p4; Fig. $12=d 4$. All specimens are figured as sinistral ones. All Figures $\times 4$.

shows morphological variation not met before. A second consideration is that Bosma's result is derived by abrasion of a molar instead of by natural wear, which may produce different results. Further, Bosma (op. cit.: 337) allocated the two abraded Pleistocene molars to "Acanthion brachyurus cf. iavanicum Cuvier". Van Weers (1985: 116117, Figs. 5, 6) has shown that Bosma's Sangiran material has clearly smaller dimensions than Hystrix brachyura Linnaeus and Hystrix javanica
(Cuvier), so we probably have to do with a species that differs from the recent species. The differences between Bosma's teeth and our material are not essential. Bosma's stages of attrition "A4", "A5", and "A6" agree with our respective classes F1, F4, and G1. Most of her patterns of the lower molars fit quite well with our wear stages: "B1" = 01 , "B2" = 03, "B3" = 04, "B4" = $\mathrm{P} 2$, "B5" is similar to $\mathrm{S} 1$, "B6" = $\mathrm{S} 1$, "B7" = S3 and "B8" = T1. Further study of the Sangiran molars is needed

Plate II. Occlusal view of upper molars (Figs. 1-4) and lower molars (Figs. 5-20) with indication of class of wear. Figs. 1, $3=$ M2; Fig. 2 = M1; Fig. 4 = P4; Figs. 5, 6, $12=$ m3; Figs. 7, $8=$ d4; Figs. 9, 10, 13, 14, 17, 19, $20=$ m1; Figs. 11, 15, 16, $18=\mathrm{m} 2$. All specimens are figurd as sinistral ones. All Figures $\times 4$. 
in order to evaluate the morphological similarity or difference with the recent forms.

Sulimski (1960) based the occurrence of five buccal folds on Hystrix material from the Pliocene of Weze in Poland. The folds "IV" and "V" in his Fig. 1 (1960: 321) are bordering a small "dentine islet", fusing medially, and this peculiarity is repeated in the other molars of that specimen. It may well be possible that we have to do here with an example of individual variation and that these two folds may be homologous with our fold IV. The dental pattern of the $\mathrm{p} 4$ of this Pliocene sample can not be allocated to one of the wear classes of the present study, but its occlusal structure is not essentially different from that of our species studied. The $\mathrm{m} 1$ in that mandible fits the wear class $\mathrm{T} 1$ with the islands 2 to 6 , and the $\mathrm{m} 2$ fits in class $\mathrm{T} 2$ with the islands 1 to 6. Sulimski (op. cit., Fig. 2) figured a series of six successive stages of the P4 in his material. These are neither based on serial sections nor on the observation of a larger series of molars, but represent hypothetical reconstructions. Some stages of this series do not fit in our results, and individual variation or the way this series was obtained may be due to this fact.

Probably the determination of structural parameters such as structural density or indentation (Schmidt-Kittler, 1984), in combination with conventional measuring of molar dimensions, will enlarge the possibilities for analysis of the occlusal patterns of porcupine molars. Facilities for this type of analysis were not available up to now, but when possible it will be applied in continued study.

\section{Acknowledgements}

I am most grateful to Dr. P.J.H. van Bree and Dr. Chr. Smeenk (curators of the Mammal Department of the Zoölogisch Museum Amsterdam and the Rijksmuseum van Natuurlijke Historie, Leiden, respectively) for the permission to study the skulls in their collections. Thanks are due to Dr. H. de Bruijn (Instituut voor Aardwetenschappen, State University of Utrecht) and
Dr. J. de Vos (Rijksmuseum van Natuurlijke Historie, Leiden) for kind cooperation and a critical reading of the manuscript. Mr. L.A. van der Laan (Zoölogisch Museum Amsterdam) is greatly acknowledged for painstaking photographic work. Mr. Th.P.M. van Groningen (Amsterdam) is thanked for kind assistance in computer use, and Mrs. R.E. Slop for correction of the English text.

\section{References}

Bosma, A.A., 1968. The influence of attrition on the dental pattern of Pleistocene Acanthion brachyurus (Hystricidae, Rodentia, Mammalia) from Java. Proc. kon. ned. Akad. Wet., (B) 71(4): 336-341.

Hooijer, D.A., 1946. Some remarks on recent, prehistoric and fossil porcupines from the Malay Archipelago. Zool. Meded., Leiden, 26: 251-267.

Nikiforowa, K.W. \& E.A. Wangenheim, 1988. Biostratigraphy of the late Pliocene-Pleistocene of Tadzhikistan: 1-125 (Acad. Sci. U.S.S.R., Moscow; in Russian).

Schmidt-Kittler, N., 1984. Pattern analysis of occlusal surfaces in hypsodont herbivores and its bearing on morphofunctional studies. Proc. kon. ned. Akad. Wet., (B) 87(4): 453-488.

Stehlin, H.G. \& S. Schaub, 1951. Die Trigonodontie der Simplicidentaten Nager. Schweiz. paleont. Abh., 67: 1-385.

Stirton, R.A., 1935. A review of the Tertiary beavers. Univ. Calif. Publ., Bull. Dept. Geol., 23(13): 391-458, 2 charts, 1 map.

Sulimski, A., 1960. Hystrix primigenia (Wagner) in the Pliocene fauna from Weze. Acta Palaeontologica Polonica, 5(3): 319-336, 2 pls.

Weers, D.J. van, 1979. Notes on Southeast Asian porcupines (Hystricidae, Rodentia) IV. On the taxonomy of the subgenus Acanthion F. Cuvier, 1823 with notes on the other taxa of the family. Beaufortia, 29(356): 215-272.

Weers, D.J. van, 1985. Hystrix gigantea, a new fossil porcupine species from Java (Rodentia: Hystricidae). Senckenbergiana lethaea, 66(1/2): 111-119.

Wood, A.E., 1974. The evolution of the Old World and New World Hystricomorphs. Symp. zool. Soc. London, 34: 21-60.

Wood, A.E. \& R.W. Wilson, 1936. A suggested nomenclature for the cusps of the cheek teeth of rodents. J. Paleont., 10(5): 388-391.

Received: 1 December 1989 